\section{ElaboraÇão de doCE DE LEITE \\ PASTOSO COM SUBSTITUIÇÃO PARCIAL \\ DOS SÓLIDOS DE LEITE POR CONCENTRADO PROTÉICO DE SORO}

Flávia Berwerth Bellarde*

\section{Introdução}

O doce de leite pastoso é um produto obtido por concentração, elaborado com ou sem adição de sólidos de origem láctea e adicionado de sacarose ou outro mono ou dissacarídeo. Sua composição é de no máximo $30 \%$ de umidade, 6 - 9\% de gordura, máximo de $2 \%$ de cinzas e mínimo de $5 \%$ de proteína (BRASIL, 2005). No leite, as proteínas estão agrupadas em duas classes: caseína $(2,7 \%)$ e proteínas do soro $(0,8 \%)$. Cada classe apresenta propriedade funcional diferenciada, proporcionando variação no produto final (BLENFORD, 1992). Assim, o soro de leite também pode ser utilizado conferindo características funcionais excelentes na produção do doce de leite (MIZUBUTI, 1994) e a substituição parcial dos sólidos de leite por concentrado protéico de soro (cps) tem apresentado vantagem econômica sem mudar significativamente a qualidade do produto.

Kelly (1986) destaca que economicamente é mais viável utilizar cps com 35\% de proteína na substituição parcial do leite em pó para confeitos em geral. Comercialmente, o soro doce em pó é mais usado que o ácido, apresentando boa solubilidade e funcionalidade numa faixa de 30 a $75 \%$ de proteína (MIZUBUTI, 1994). Em um estudo realizado por Heimlich et al. (1994), a substituição parcial (50\%) de leite por cps a 31,5\% de proteína resultou num doce semelhante ao tradicional quanto à sua espalhabilidade e a sua relação entre açúcar e a proteína, que influenciou o desenvolvimento da cor através da reação de Maillard.

Os produtos de soro, segundo Cândido e Campos (1996), são indicados para todos os produtos lácteos por possuírem propriedades funcionais como a

*Professora Doutora do curso de Nutrição do Centro Universitário de Araraquara - UNIARA (flavia.bellarde@uol.com.br). capacidade de formação de gel, viscosidade, poder emulsificante, capacidade de retenção de água, que conferem uma série de benefícios estruturais e nutricionais ao produto final. E, como os cps são sistemas multifuncionais (ANTUNES et al., 2003; LOURENÇO, 2000), eles vêm sendo adicionados a diversos alimentos com o objetivo de modificar as suas propriedades em vários produtos, como mostra o trabalho de Soares et al. (2002) que produziram um requeijão em barra com teor reduzido de gordura e característica semelhante ao produto tradicional.

Muitas vezes, a formulação de um novo produto é feita por tentativa e erro, porém, o conhecimento das características químicas e funcionais de cada ingrediente pode encurtar o tempo de desenvolvimento. Como ainda hoje não se tem um aproveitamento máximo do soro devido o alto custo e a dificuldade de processá-lo, mas há um grande aumento na produção nacional de queijo, que tem gerado um crescente volume do soro, causando problemas práticos e econômicos de poluição ambiental, esse trabalho teve como objetivo elaborar um doce de leite com substituição parcial dos sólidos de leite por cps de modo a obter um produto com características semelhantes ao doce tradicional, em relação à cor e textura (LOBO; SILVA, 2003).

\section{Material e métodos}

\section{Matéria-prima}

As matérias-primas utilizadas na elaboração do doce de leite foram: leite em pó integral (26\% de proteína, 37\% de lactose, $26 \%$ de gordura, $4 \%$ de umidade e $6 \%$ de cinzas); concentrado protéico de soro (35\% de proteína, 52\% de lactose, $3 \%$ de gordura, $6 \%$ de cinzas e $7 \%$ de umidade), obtido do soro doce por ultrafiltração. Outros componentes utilizados foram a sacarose refinada, o xarope de glicose (80\%) e o bicarbonato de sódio.

\section{Métodos}

Processamento do doce

O doce de leite foi preparado a partir de formulação utilizada por Heimlich et al. (1994). Após a pesagem das matérias-primas, a água foi aquecida à $70^{\circ} \mathrm{C}$ para facilitar a diluição do material. A adição do bicarbonato de sódio proporcionou a correção da acidez. O produto homogeneizado (65\% de sólidos) e aquecido à $85^{\circ} \mathrm{c}$ foi então recravado e submetido ao tratamento térmico $\left(120^{\circ}\right.$ c / 10 minutos), resfriado e estocado em temperatura ambiente.

A produção do doce de leite englobou três tratamentos: controle (sem substituição de cps) e, com 20 e 30\% de substituição, as formulações foram: sacarose (33\%), xarope de glicose (8\%), água (34\%), sólidos do leite (25\%) e bicarbonato de sódio (2,44 g / 100 g). 
Determinação da cor

A cor do doce de leite foi determinada em colorímetro Minolta, em sistema Hunterlab em três escalas (l, a, b) segundo Ferreira et al. (1989).

Determinação da textura

A análise do perfil de textura foi realizada no texturômetro ta.xt ${ }_{2}$, a partir das condições de Pauletti et al (1992); probe acrílico de $20 \mathrm{~mm}$, força em compressão de $5 \mathrm{~g}$ e velocidade de $10 \mathrm{~mm} / \mathrm{s}$. As características analisadas foram dureza e adesividade.

Determinação do hidroximetilfurfural (hmf)

A determinação do hmf foi realizada pelo método descrito em Pinto e Pombo (1984), cuja técnica se baseia na medida da cor amarela na reação entre o ácido tiobarbitúrico e o hmf.

Análise estatística

Os resultados foram avaliados pela análise de variância (anova) e a comparação das médias foi através do teste de Tukey (a 5\% de significância), utilizando o programa SAS (1992).

\section{Resultados e discussão}

A tabela 1 apresenta os valores de cor para as formulações estudadas. Pode-se observar que houve diferença significativa a 5\% para a luminosidade (l) nas três amostras estudadas. Na amostra sem substituição, o produto obtido foi mais escuro. Quando se comparam as duas substituições, à 30\% obteve-se um produto mais escuro que à $20 \%$ (figura 1). Além disso, as amostras com cps se apresentaram menos avermelhadas e com maior pigmentação amarela que a amostra com leite em pó.

Nessas formulações, verificando a relação existente entre carboidrato e proteína, encontrou-se: 0,7 para a tradicional; 0,17 para 30\% e 0,14 para 20\%, confirmando nesse estudo que quanto maior essa relação, maior a cor formada indiferente da temperatura estudada, segundo Pauletti et al (1996).

A presença do hmf indica as primeiras manifestações do escurecimento do leite. No doce de leite, o hmf aumenta com a concentração do açúcar, no tempo de aquecimento, com variações dos ingredientes e quantidade de açúcares redutores, segundo Pinto e Pombo (1984). A formulação sem substituição apresentou-se com maior formação de hmf, seguida da amostra com $20 \%$ e 30\%. Comparando-se o valor encontrado com a presença de açúcares redutores, verificou-se que o hmf aumentou em função da sua quantidade, que foi: $16 \%$ para a formulação tradicional; $16,5 \%$ para $20 \%$ e $15 \%$ para $30 \%$. Os mesmos autores destacam que os valores de hmf entre 3,8 a 4,8 umol/l normalmente apresentam doces com melhor aceitação quanto à cor.
Tabela 1. Resultados de cor para as amostras com substituição parcial de soro.

\begin{tabular}{|c|c|c|c|c|}
\hline amostras & $\mathbf{l}$ & a & b & hmf (umol/l) \\
\hline $20 \%$ substituição & $59,70^{\mathrm{a}}$ & $5,24^{\mathrm{b}}$ & $26,45^{\mathrm{a}}$ & $3,84^{\mathrm{a}}$ \\
\hline $30 \%$ substituição & $58,20^{\mathrm{b}}$ & $4,68^{\mathrm{b}}$ & $26,45^{\mathrm{a}}$ & $2,48^{\mathrm{a}}$ \\
\hline sem substituição & $50,77^{\mathrm{c}}$ & $7,45^{\mathrm{a}}$ & $24,21^{\mathrm{a}}$ & $4,01^{\mathrm{a}}$ \\
\hline
\end{tabular}

Letras iguais na mesma coluna, amostras não diferem entre si a 5\%.

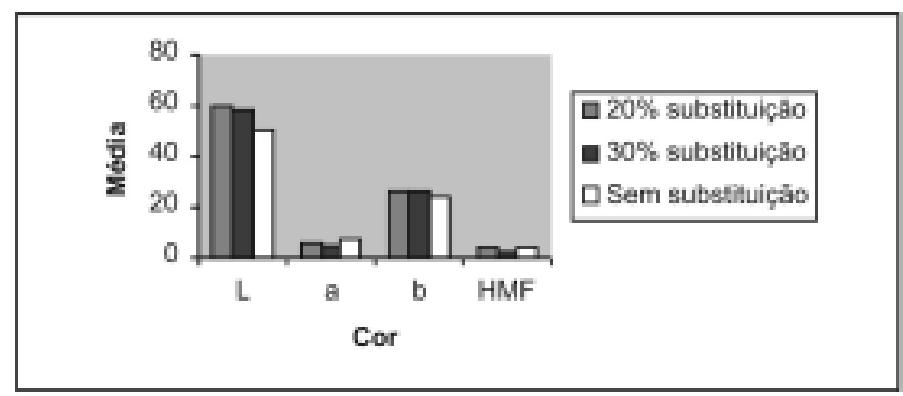

Figura 1. Comparação de cor para as amostras com substituição parcial de soro.

Para o estudo de textura (tabela 2, figura 2), a medida da dureza e a adesividade da amostra mostrou o quanto as proteínas do soro são sensíveis às temperaturas utilizadas. A amostra sem soro foi a mais dura e adesiva, seguida da amostra com $30 \%$ de substituição e, posteriormente, com 20\%. Hough et al (1992) destacaram que os componentes do doce de leite influenciam a textura e Pauletti et al.(1996) destacam que há pouca informação na literatura sobre a cinética da textura do doce de leite. Mas, de um modo geral, as soluções de moléculas longas têm maior viscosidade do que as globulares e, quanto mais caseína presente, menor o tempo de gelificação.

Tabela 2. Resultados de textura para as amostras com substituição parcial de soro.

\begin{tabular}{|c|c|c|}
\hline amostras & dureza & adesividade \\
\hline $20 \%$ substituição & $10,90^{\mathrm{c}}$ & $-1,14^{\mathrm{a}}$ \\
\hline $30 \%$ substituição & $18,33^{\mathrm{b}}$ & $-25,05^{\mathrm{b}}$ \\
\hline sem substituição & $42,83^{\mathrm{a}}$ & $-33,57^{\mathrm{C}}$ \\
\hline
\end{tabular}

Letras iguais na mesma coluna, amostras não diferem entre si a 5\%. 


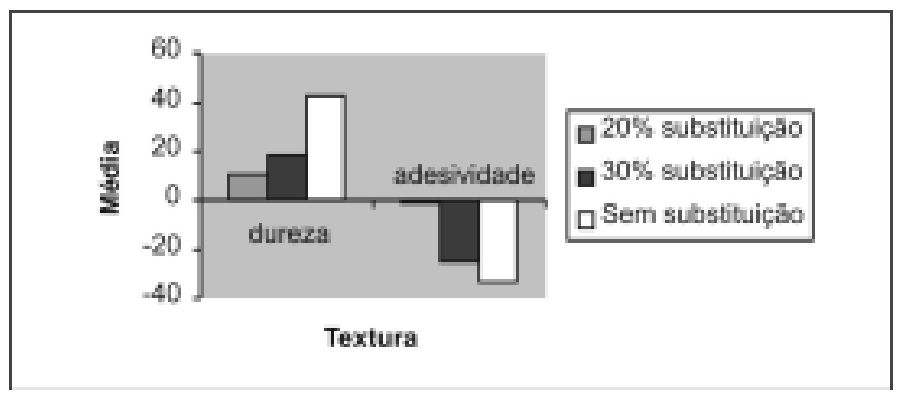

Figura 2. Comparação de textura para as amostras com substituição parcial de soro.

\section{Conclusões}

Comparando as amostras de doce de leite elaboradas parcialmente com concentrado protéico de soro, verificou-se que, com 30\% de substituição, o doce de leite se apresentou mais próximo da cor do doce tradicional, quando comparado com 20 \% de substituição. Para a análise da dureza do doce, observou-se que a substituição de 30 \% também forneceu um produto mais firme. De um modo geral, quando se trabalha com substituição nos sólidos do leite, as modificações são mais efetivas na textura do que na cor do produto.

\section{Referências:}

ANTUNES, A.E.C.; MOTTA; M.P.; ANTUNES, A.J. Perfil de textura e capacidade de retenção de água de géis ácidos de concentrado protéico de soro de leite. Ciência e Tecnologia de Alimentos: v.33 (supl), p.183-89, 2003

BLENFORD, D. Developing dairy derivates. Food Ingredients Processing International, n.3, p.10-13, 1992.

BRASIL. Ministério da Agricultura e do Abastecimento. Secretaria de Defesa Agropecuária. Departamento de Inspeção de Produtos de Origem Animal. Portaria ${ }^{\circ}$. 354, de 04 de setembro de 1997. Disponível em: http:/ www.agricultura.gov.br/das/dipoa/por.354.html. Acesso em: 23 jun. 2005.

CÂNDIDO, L.M.B.; CAMPOS, A.M. Alimentos para fins especiais: dietéticos. São Paulo: Livraria Varela, p.115-330, 1996.
FERREIRA, V.L.P.; HOUGH, G.; YOTSUYANOGI, K. Cor de doce de leite pastoso. Coletânea do Instituto de Tecnologia de Alimentos, v.9, n.2, p. 134-145, 1989.

HEIMLICH, W.; BORQUEZ, R.; CÉSPEDES, I. Effect of milk replacement by whey protein concentrates on the rheological properties of dulce de leche. Lebensmittel-Wissenschaft und Technologie, v.27, n.3, p.289-91, 1994.

HOUGH, G.; BRATCHELL, N.; MACDOUGALL, D.B. Sensory profiling of dulce de leche, a dairy based confectionary product. Journal of Sensory Studies, v.7, n.1, p.157-78, 1992.

KELLY, P.M. Dried milk protein products. Journal of the Society of Dairy Technology, v.39, n.3, p.81-85, 1986.

LOBO, A.R.; SILVA, G.M.L. Aspectos tecnológicos de produtos de panificação e massas alimentícias com teor calórico reduzido. Boletim da SBCTA, v.37, n.1, p.1-8, 2003.

LOURENÇO, E.J. Tópicos de Proteínas de Alimentos. Jaboticabal: Funep, 2000.

MIZUBUTI, I.Y. Soro de leite: composição, processamento e utilização na alimentação. Revista Cultural e Científica da Universidade Estadual de Londrina, v.15, n.3, p.81-85, 1986.

PAULETTI, M.S.; CALIO, C.; IZQUIERDO, L. ;COSTELL, E. Color y textura del dulce de leche. seleción de metodos instrumentales para el control de calidad industrial. Revista Española de Ciência y Tecnologia de Alimentos, v.32, n.3, p.291-305, 1992

PAULETTI, M.S.; CASTELAO, E.; BERNARDI, M.C. Influence of soluble solids, acidity and sugar on the color of dulce de leche. Food Science and Technology International, v.2, p.45-49, 1996.

PINTO, A.P.E.F.; POMBO, A.W. 5-hidroximetilfurfural no doce de leite. Revista do Instituto de Laticínios Cândido Tostes, v.39, n.236, p.9-11, 1984.

SAS - user's procedures guide. version 6, Cary: sas institute, 1992. 
SOARES, F.M.; FONSECA, M.; MARTINS R.T. et al. Influência do

concentrado protéico de soro na composição do requeijão em barra com teor reduzido de gordura. Arquivo Brasileiro de Medicina Veterinária e

Zootecnia, v.54, n.6, p.1-7, 2002.

\section{Resumo:}

A substituição parcial de leite por concentrado protéico de soro permitiu a produção de um doce que manteve as características de cor e textura próximas ao produto tradicional. O doce de leite foi fabricado com duas substituições (20 e 30\%), comparadas com uma formulação tradicional com leite em pó integral. Houve mais diferença entre as amostras no estudo de textura do que na análise da cor do produto, mostrando a complexidade da composição protéica no desenvolvimento da textura.

\section{Palavras-chave:}

Doce de Leite, Concentrado Protéico de Soro, Sólidos de Leite. 